\title{
Digital Media as a Proponent for Healthy Aging in the Older Chinese American Population: Longitudinal Analysis
}

\author{
Sara Shu ${ }^{1,2}$, BS; Benjamin K P Woo ${ }^{1}$, MD \\ ${ }^{1}$ University of California, Los Angeles, Sylmar, CA, United States \\ ${ }^{2}$ College of Osteopathic Medicine of the Pacific, Western University of Health Sciences, Pomona, CA, United States
}

\section{Corresponding Author:}

Sara Shu, BS

University of California, Los Angeles

14445 Olive View Drive

Sylmar, CA, 91342

United States

Phone: 17472103830

Email: $\underline{\text { sarashu@gmail.com }}$

\section{Abstract}

Background: Ensuring health literacy among underserved populations is essential amid an aging population. Accessible and appropriate (both culturally and linguistically) information is important when considering digital media education for older Chinese Americans.

Objective: This study aims to investigate how social media fare over time in disseminating health information and how we may most effectively educate this population.

Methods: For this study, 5 geriatric-themed educational videos about Parkinson disease, fall prevention, gastrointestinal health, oral health, and pulmonary disease were uploaded to YouTube. Data were collected over a 40-month period. Descriptive statistics and chi-square analysis were used to compare results from the first and second 20-month periods.

Results: In 40 months, the 5 videos in aggregate accrued 1171.1 hours of watch time, 7299 views, and an average view duration of 9.6 minutes. Comparing the first and second 20-month periods, there was a significant increase in mobile device usage, from $79.4 \%$ (3541/4458) to $83.3 \%$ (2367/2841). There was no significant difference in the usage of various external traffic sources and methods of sharing, with WhatsApp accounting for the majority of sharing in both 20-month periods.

Conclusions: Our study provides insight into where to focus future strategies to optimize digital media content, and how to best recruit, direct, and disseminate health education to an older adult Chinese American population. Combining the success of YouTube, social media, and messaging platforms such as WhatsApp can help to transcend cultural and linguistic barriers to promote healthy aging.

(JMIR Aging 2020;3(1):e20321) doi: 10.2196/20321

\section{KEYWORDS}

geriatrics; health promotion; health education; social media; Parkinson disease; fall prevention; oral health; pulmonary disease; gastrointestinal health

\section{Introduction}

By the year 2060, there will be roughly 98 million Americans aged over 65 years, roughly 1 in 5 people, in large part due to the aging baby boom generation [1]. With aging come inevitable challenges of chronic diseases, falls, physical activity, oral health, and mental health concerns that can largely impact quality of life. Parkinson disease, the second-most common neurodegenerative disease after Alzheimer disease, is expected to affect nearly 1.2 million Americans by 2030 [2]. Similarly, falls have become a leading cause of injury among older adults, with a projected 100,000 fatal falls per year and direct treatment costs expected to reach US $\$ 101$ billion by 2030 [3]. Challenges like these result in significant financial and emotional burden for families and caregivers, emphasizing the need to optimize care for this aging population in the coming decades.

The older adult population is not only growing, but also becoming more racially and ethnically diverse, making inequities in health and access to resources more apparent [4]. Nationally implemented healthy aging initiatives, programs, 
and services therefore need to consider the unique needs of different subpopulations, and provide culturally and linguistically appropriate materials. Chinese Americans are one minority group that underutilize health resources; as a result, they are at risk for delayed diagnoses, and suboptimal treatment and management of a variety of chronic health conditions [5-7]. There remain cultural, educational, and linguistic barriers that present challenges in health literacy, access, and information dissemination $[8,9]$.

Amid an aging population, distribution of health education over the internet and social media can contribute to healthy aging. Today, more and more Americans turn to the internet for health information. Social media has transformed into a platform for health communication among the general public, patients, and health professionals [10]. Among them, YouTube has become one of the world's most popular social media platforms [11]. Digital health education dissemination holds promise in helping to bridge cultural and linguistic barriers that have previously precluded populations from access to such information. It therefore behooves us to study how populations utilize and access digital health information to tailor how best to distribute and promote health literacy among underserved populations.

Previous studies have shown that YouTube is effective in delivering dementia knowledge to older Chinese Americans [12-14]. Another study has analyzed Twitter as a health information relaying platform [15]. Furthermore, Facebook advertising has proven promising for the dissemination of dementia and hypertension information [16,17]. In addition, more recent studies have suggested a rise in WhatsApp use among older Chinese Americans in sharing dementia education $[18,19]$. However, few studies have investigated other health education topics (even in aggregate) and the role of social media in their dissemination to this population. In this paper, we aim to determine the efficacy of YouTube as a medium for delivering a variety of aging-related health education resources, and study the change in modes of viewing and sharing across different social media platforms over time. To our knowledge, this is the first longitudinal study of 5 different geriatric-themed videos in the older Chinese American population.

\section{Methods}

\section{YouTube}

A board-certified psychiatrist delivered 5 geriatric-themed educational talk shows in Cantonese at the radio station KMRB AM1430 in Los Angeles. Real-time recordings were then individually uploaded to YouTube. Average video length was 36.4 minutes. Topics addressed include Parkinson disease, fall prevention, gastrointestinal health, oral health, and pulmonary disease.

\section{Sample}

The sample of this study included YouTube video viewers over a 40-month period (November 2016 to March 2020).

\section{Statistical Analysis}

Data were extrapolated from YouTube Analytics. Parameters recorded included number of views, watch time, average view duration, devices used to view, traffic sources, and modes and means of sharing via various social media platforms. The first and second 20-month intervals were dichotomized (November 2016 to July 2018, and July 2018 to March 2020). Descriptive statistics and chi square test were used to compare data collected between the first and second 40-month intervals.

This study used anonymous data exclusively collected by YouTube. A waiver for Institutional Review Board exemption was obtained through the Human Subjects Protection Committee of University of California, Los Angeles.

\section{Results}

In 40 months, the 5 videos in aggregate accrued a total of 1171.1 hours of watch time and 7299 views, and an average view duration of 9.6 minutes. A breakdown of each of the 5 video topics is shown in Table 1. Data were then dichotomized into two 20-month intervals: November 2016 to July 2018, and July 2018 to March 2020. Between November 2016 and July 2018, the recorded YouTube videos accrued a total of 738.6 hours of watch time and 4458 views, and an average view duration of 9.9 minutes. Between July 2018 and March 2020, there were 432.5 hours of watch time and 2841 views, and the average view duration was 9.1 minutes. Overall, the latter 20 months had a decrease in total watch time (738.6 versus 432.5 hours), the number of views (4458 versus 2841 views), and the average view duration (9.9 versus 9.1 minutes).

Table 1. Statistics of 5 videos over 40 months.

\begin{tabular}{lllll}
\hline Video topics & Number of views & Hours watched & Average view duration (minutes) & Total video length (minutes) \\
\hline Parkinson disease & 3092 & 501.5 & 9.7 & 38 \\
Falls & 1990 & 352.6 & 10.6 & 37 \\
Constipation and diarrhea & 1076 & 112.4 & 6.3 & 27.5 \\
Oral health & 636 & 107.7 & 10.2 & 39 \\
Pulmonary disease & 505 & 96.9 & 11.5 & 40.5 \\
Total & 7299 & 1171.1 & 9.6 & 182 \\
\hline
\end{tabular}


Average view duration on computers increased $13.0 \%$ from 8.4 to 9.5 minutes between the first and second 20-month periods. In comparison, average view duration on mobile devices (mobile phones and tablets) decreased $6.9 \%$ from 10.9 to 10.2 minutes. Despite an overall decrease in views in the second 20-month period, the relative usage of computers decreased from $20.6 \%$
(917/4458) to $16.7 \%(474 / 2841)$, while relative mobile usage increased from $79.4 \%$ (3541/4458) to $83.3 \%$ (2367/2841). The increase in relative mobile device usage compared to computer usage from the first to the second 20 -month period is statistically significant (79.4\% versus $83.3 \%, \chi_{1}^{2}=17.0, P<.001$; Table 2$)$.

Table 2. Devices used for viewing videos.

\begin{tabular}{|c|c|c|c|c|c|c|}
\hline \multirow[t]{2}{*}{ Devices } & \multicolumn{3}{|c|}{ November 2016 to July 2018} & \multicolumn{3}{|c|}{ July 2018 to March 2020} \\
\hline & $\begin{array}{l}\text { Number of } \\
\text { views }\end{array}$ & Hours watched & $\begin{array}{l}\text { Average view duration } \\
\text { (minutes) }\end{array}$ & $\begin{array}{l}\text { Number of } \\
\text { views }\end{array}$ & Hours watched & $\begin{array}{l}\text { Average view duration } \\
\text { (minutes) }\end{array}$ \\
\hline Computer & 917 & 129 & 8.4 & 474 & 74.7 & 9.5 \\
\hline Mobile device & 3541 & 609.6 & 10.9 & 2367 & 357.8 & 10.2 \\
\hline Total & 4458 & 738.6 & 9.9 & 2841 & 432.5 & 9.1 \\
\hline
\end{tabular}

Looking at traffic sources, externally sourced views remained the same between the two 20-month periods: $6.9 \%(308 / 4458)$ and $6.9 \%$ (198/2841) of views, respectively. Of external sources, the top platforms were Facebook, Google search, and WhatsApp. Over 40 months, traffic generated from Facebook drastically decreased from $1.8 \%$ to $0 \%$ of total views (82/4458 versus $0 / 2841$ ), Google search increased from $0.9 \%$ to $1.4 \%$ of total views (41/4458 versus 39/2841), and WhatsApp decreased from $0.8 \%$ to $0.5 \%$ of total views (34/4458 versus $15 / 2841)$. Despite the significant drop in Facebook-generated traffic, there was no significant difference in traffic generated through Google search $\left(0.9 \%\right.$ versus $\left.1.4 \%, \chi_{1}^{2}=3.7, P=.06\right)$ or WhatsApp $(0.8 \%$ versus $0.5 \%, \chi_{1}^{2}=1.7, P=.19$ ) between the two 20 -month periods (Table $3)$.

Table 3. Traffic sources.

\begin{tabular}{|c|c|c|c|c|c|c|}
\hline \multirow[t]{2}{*}{ Traffic sources } & \multicolumn{3}{|c|}{ November 2016 to July 2018} & \multicolumn{3}{|c|}{ July 2018 to March 2020} \\
\hline & $\begin{array}{l}\text { Number of } \\
\text { views }\end{array}$ & Hours watched & $\begin{array}{l}\text { Average view duration } \\
\text { (minutes) }\end{array}$ & $\begin{array}{l}\text { Number of } \\
\text { views }\end{array}$ & Hours watched & $\begin{array}{l}\text { Average view duration } \\
\text { (minutes) }\end{array}$ \\
\hline \multicolumn{7}{|l|}{ Top 4 traffic sources } \\
\hline Suggested videos & 2024 & 375.9 & 11.1 & 917 & 161.4 & 10.6 \\
\hline YouTube search & 945 & 102.7 & 6.5 & 790 & 98.4 & 7.5 \\
\hline Browse features & 731 & 149 & 12.2 & 715 & 118.4 & 9.9 \\
\hline External & 308 & 34.4 & 6.7 & 198 & 22.4 & 6.8 \\
\hline \multicolumn{7}{|c|}{ Top 4 external traffic sources } \\
\hline Facebook & 82 & 7 & 5.1 & 0 & 0 & 0 \\
\hline Google search & 41 & 2.6 & 3.8 & 39 & 5.3 & 8.1 \\
\hline WhatsApp & 34 & 6.4 & 11.3 & 15 & 0 & 12 \\
\hline Other & 6 & 1.3 & 13 & 6 & 0.3 & 3 \\
\hline
\end{tabular}

In the first 20 months, the videos were shared 107 times through various sharing services. In the second 20 months, the videos were shared 56 times, and WhatsApp was the most utilized

sharing method. However, comparing the two time periods, there is no significant difference in the usage of WhatsApp for sharing $\left(54.2 \%\right.$ versus $58.9 \%, \chi_{1}^{2}=0.3, P=.56$; Table 4$)$.

Table 4. Use of sharing services during both study periods.

\begin{tabular}{lll}
\hline Sharing services & $\begin{array}{l}\text { November 2016 to July 2018 (N=107) } \\
\text { Shares, } \mathrm{n}(\%)\end{array}$ & $\begin{array}{l}\text { July 2018 to March 2020 (N=56) } \\
\text { Shares, n (\%) }\end{array}$ \\
\hline WhatsApp & $58(54.2)$ & $33(58.9)$ \\
SMS text messaging & $7(6.6)$ & $1(1.8)$ \\
Email & $5(4.7)$ & $4(7.1)$ \\
Facebook & $1(0.9)$ & $1(1.8)$ \\
Other & $36(33.6)$ & $17(30.4)$ \\
\hline
\end{tabular}




\section{Discussion}

\section{Principal Findings}

The majority of older adults have multiple chronic conditions [20]. Rather than focusing on a single condition or disease, this study is the first to analyze in aggregate the performance of 5 aging-relevant educational videos over 40 months. By investigating how older Chinese Americans are utilizing different platforms for viewing and sharing videos, we gain valuable insight into how we may tailor future health education dissemination to this population. Overall, the latter 20-month period had a decrease in total watch time (738.6 versus 432.5 hours), the number of views (4458 versus 2841 views), and average view duration (9.9 versus 9.1 minutes). A previous study determined that 6 minutes is the average engagement time for online educational videos of varying lengths [21]. Average view duration over the 40-month period was 9.6 minutes, demonstrating that these videos succeeded in maintaining viewers' attention and engagement.

Chi-square analysis revealed that mobile devices remain the top device used for viewing these educational videos; indeed, they experienced a statistically significant increase in usage from $79.4 \%(3541 / 4458)$ to $83.3 \%(2367 / 2841)$ over the 40 months, while computer usage decreased from $20.6 \%$ (917/4458) to $16.7 \%(474 / 2841)$. As there is a continued shift from computer to mobile device usage, ensuring mobile device compatibility in future digital health communication should be a priority. Furthermore, it becomes important to examine and understand any barriers and challenges that this population faces to better shape the design of future platforms and systems of health-related communication via mobile device. Barriers and challenges may include functional limitations such as visual or motor impairment, having low technology literacy, or being adverse to new methods. Work can be done to develop more user-friendly interfaces to maximize potential use among older adults. The development of user-friendly interfaces is not limited to only mobile device but extends to the development of future technologies such as voice-activated speaker devices, and the growing number of products on e-commerce platforms tailored for an aging population [22,23].

With regards to external traffic sources, while there was a significant decrease in Facebook-generated traffic, there was no significant change in Google search and WhatsApp traffic. Our study reveals an increase in Google search from $0.9 \%$ to $1.4 \%$ of total views $(41 / 4458$ versus $39 / 2841)$ and a decrease in WhatsApp from $0.8 \%$ to $0.5 \%$ of total views (34/4458 versus 15/2841). Although WhatsApp remains the top sharing service, there was no significant change in the amount of sharing that occurred between the two periods. Taken together, this study entertains questions of how to increase visibility via Google search amid a saturating field, and how to promote viewer sharing via WhatsApp. For example, future studies can investigate whether using long tail keywords (more specific keyword phrases) increase visibility via Google search.

It has previously been shown that digital recruitment via Facebook and, more recently, Instagram, is promising in directing individuals to health education materials $[16,17,24]$.
However, the effects last only as long as the recruitment period. If strong and effective advertising is conducted at the beginning of a particular study period, the media in question could potentially experience longer-lasting visibility across future searches via Google. Work therefore needs to be done to devise novel or stronger methods of advertising (eg, Facebook, Instagram, or equivalent), and to publicize the availability of these resources to ensure enduring visibility and impact for years to come.

Finally, previous studies have shown that WhatsApp has become the preferred means of sharing dementia knowledge and is used more for its sharing capability than for its viewing function $[18,19]$. Although our data only provide a 40-month window into the performance of 5 different aging-themed educational videos, our study acknowledges WhatsApp's potential to become a successful platform for disseminating information for healthy aging to the older Chinese American population. As not only a social media platform, but also a personal messaging system, WhatsApp has the potential to reach a wide audience. With so many resources now available for the internet searcher, for any single resource to have a significant impact, the methods of dissemination and incentives for viewers to share need to evolve. Future studies could investigate the strategic placement of reminders to, for example, "share via WhatsApp if you found this useful." Other studies could incorporate the use of visual WhatsApp icons (specifically, the WhatsApp share button) to prompt and facilitate sharing via WhatsApp.

\section{Limitations}

There are several limitations in this study. As the videos used in this study were filmed in Cantonese, the audience was limited to those in the Chinese American population who are fluent in Cantonese. Furthermore, each video retained a rather short average viewing duration of 9.9 to 9.1 minutes, which is a fraction of the average video length of 36.4 minutes. Future studies should consider shortening video lengths and incorporating more interactive elements to increase audience engagement time with the goal of improved audience experience and greater retention of educational information. As a retrospective longitudinal analysis, data collected were limited to that collected by YouTube Analytics. Being able to design a prospective study would enable us to focus on WhatsApp as a sharing service, or the effectiveness of various recruitment methods.

\section{Conclusions}

The internet and usage of social media are continually evolving and changing the way in which we communicate health information among individuals and the medical community. YouTube is a promising and valuable tool to deliver culturally and linguistically appropriate health education to isolated populations. More studies need to be done to harness technologies now available on mobile devices with meaningful improvement in the health of older adults. In addition, future studies could investigate how WhatsApp can achieve its full potential as a top platform for health information dissemination. As such, further studies looking at both short- and long-term strategies and outcomes are necessary to learn how different populations of interest search for and disseminate information 
to best be able to serve and deliver pertinent health education, ensure healthy aging, and promote healthy outcomes.

\section{Conflicts of Interest}

None declared.

\section{References}

1. Administration for Community Living. 2017 Profile of older Americans URL: https://acl.gov/sites/default/files/ Aging\%20and\%20Disability\%20in\%20America/2017OlderAmericansProfile.pdf [accessed 2020-05-02]

2. Marras C, Beck JC, Bower JH, Roberts E, Ritz B, Ross GW, Parkinson's Foundation P4 Group. Prevalence of Parkinson's disease across North America. NPJ Parkinsons Dis 2018 Jul 10;4(21):21 [FREE Full text] [doi: 10.1038/s41531-018-0058-0] [Medline: 30003140$]$

3. Houry D, Florence C, Baldwin G, Stevens J, McClure R. The CDC Injury Center's response to the growing public health problem of falls among older adults. Am J Lifestyle Med 2016;10(1):74-77 [FREE Full text] [doi: 10.1177/1559827615600137] [Medline: 26688674]

4. De Biasi A, Wolfe M, Carmody J, Fulmer T, Auerbach J. Creating an Age-Friendly Public Health System. Innov Aging 2020;4(1):igz044 [FREE Full text] [doi: 10.1093/geroni/igz044] [Medline: 32405542]

5. Woo BK. Dementia Health Promotion for Chinese Americans. Cureus 2017 Jun 29;9(6):e1411 [FREE Full text] [doi: 10.7759/cureus.1411] [Medline: 28856076]

6. Woo BK, Mehta P. Examining the differences in the stigma of dementia and diabetes among Chinese Americans. Geriatr Gerontol Int 2017 May 02;17(5):760-764. [doi: 10.1111/ggi.12782] [Medline: 27137751]

7. Ho EY, Woo BKP. Dementia knowledge and information seeking of Chinese Americans. J Am Geriatr Soc 2013 Apr 14;61(4):647-648. [doi: 10.1111/jgs.12194] [Medline: 23581920]

8. Nguyen GT, Bowman MA. Culture, language, and health literacy: communicating about health with Asians and Pacific Islanders. Fam Med 2007 Mar;39(3):208-210 [FREE Full text] [Medline: 17323213]

9. Tsiang JT, Woo BK. Comparison of Online Dementia Information in Chinese and in English Languages. Cureus 2017 Oct 28;9(10):e1808 [FREE Full text] [doi: 10.7759/cureus.1808] [Medline: 29308336]

10. Moorhead SA, Hazlett DE, Harrison L, Carroll JK, Irwin A, Hoving C. A new dimension of health care: systematic review of the uses, benefits, and limitations of social media for health communication. J Med Internet Res 2013 Apr;15(4):e85 [FREE Full text] [doi: 10.2196/jmir.1933] [Medline: 23615206]

11. Kwok TM, Singla AA, Phang K, Lau AY. YouTube as a source of patient information for varicose vein treatment options. J Vasc Surg Venous Lymphat Disord 2017 Mar;5(2):238-243. [doi: 10.1016/j.jvsv.2016.10.078] [Medline: 28214492]

12. Zheng X, Woo BK. E-mental health in ethnic minority: A comparison of youtube and talk-based educational workshops in dementia. Asian J Psychiatr 2017 Feb;25:246-248. [doi: 10.1016/j.ajp.2016.12.002] [Medline: 28262161]

13. Lam NH, Woo BK. Exploring the role of YouTube in delivering dementia education to older Chinese. Asian J Psychiatr 2018 Jan;31:25-26. [doi: 10.1016/j.ajp.2017.12.022] [Medline: 29324268]

14. Lam NHT, Woo BKP. YouTube as a New Medium for Dementia Education Among Chinese Americans. Community Ment Health J 2019 Oct 22;56(3):435-439. [doi: 10.1007/s10597-019-00493-7] [Medline: 31641910]

15. Cheng TY, Liu L, Woo BK. Analyzing Twitter as a Platform for Alzheimer-Related Dementia Awareness: Thematic Analyses of Tweets. JMIR Aging 2018 Dec 10;1(2):e11542 [FREE Full text] [doi: 10.2196/11542] [Medline: 31518232]

16. Dunn PH, Woo BKP. Facebook recruitment of Chinese-speaking participants for hypertension education. J Am Soc Hypertens 2018 Sep;12(9):690-692. [doi: 10.1016/j.jash.2018.06.017] [Medline: 30054194]

17. Lam NH, Woo BK. Digital Media Recruitment for Fall Prevention Among Older Chinese-American Individuals: Observational, Cross-Sectional Study. JMIR Aging 2018 Nov 01;1(2):e11772 [FREE Full text] [doi: 10.2196/11772] [Medline: 31518249]

18. Nguyen B, Woo BKP. Sharing is Caring: WhatsApp as a method of disseminating dementia knowledge to elderly Chinese Americans. Int Psychogeriatr 2019 Jun 21;32(2):281-282. [doi: 10.1017/s1041610219000656]

19. Shu S, Woo BKP. The Roles of YouTube and WhatsApp in Dementia Education for the Older Chinese American Population: Longitudinal Analysis. JMIR Aging 2020 Apr 13;3(1):e18179 [FREE Full text] [doi: 10.2196/18179] [Medline: 32281940 ]

20. Woo BKP, Daly JW, Allen EC, Jeste DV, Sewell DD. Unrecognized medical disorders in older psychiatric inpatients in a senior behavioral health unit in a university hospital. J Geriatr Psychiatry Neurol 2003 Jun 29;16(2):121-125. [doi: 10.1177/0891988703016002011] [Medline: 12801163]

21. Guo P, Kim J, Rubin R. How video production affects student engagement: an empirical study of MOOC videos. 2014 Presented at: First ACM Conference on Learning @ Scale; March 4, 2014; Atlanta p. 41-50. [doi: 10.1145/2556325.2566239]

22. Woo BKP. Dementia-Related Products on an e-Commerce Platform. JMIR Biomed Eng 2020 Mar 30;5(1):e17514 [FREE Full text] [doi: $\underline{10.2196 / 17514}$ ]

23. Chung S, Woo BK. Using Consumer Perceptions of a Voice-Activated Speaker Device as an Educational Tool. JMIR Med Educ 2020 Apr 24;6(1):e17336 [FREE Full text] [doi: 10.2196/17336] [Medline: $\underline{\text { 32329740] }}$ 
24. Lam NHT, Woo BKP. Efficacy of Instagram in Promoting Psychoeducation in the Chinese-Speaking Population. Health Equity 2020 Apr 01;4(1):114-116 [FREE Full text] [doi: 10.1089/heq.2019.0078] [Medline: 32258963]

Edited by J Wang; submitted 15.05.20; peer-reviewed by T Kawashita, T Dunnsiri, K Chong; accepted 21.05.20; published 16.06.20

Please cite as:

Shu $S$, Woo BKP

Digital Media as a Proponent for Healthy Aging in the Older Chinese American Population: Longitudinal Analysis

JMIR Aging 2020;3(1):e20321

URL: http://aging.jmir.org/2020/1/e20321/

doi: $10.2196 / 20321$

PMID: 32543447

CSara Shu, Benjamin K P Woo. Originally published in JMIR Aging (http://aging.jmir.org), 16.06.2020. This is an open-access article distributed under the terms of the Creative Commons Attribution License (https://creativecommons.org/licenses/by/4.0/), which permits unrestricted use, distribution, and reproduction in any medium, provided the original work, first published in JMIR Aging, is properly cited. The complete bibliographic information, a link to the original publication on http://aging.jmir.org, as well as this copyright and license information must be included. 